\title{
Wing feather moult and age determination of Snowy Owls Bubo scandiacus
}

\author{
Roar Solheim \\ Agder Natural History Museum and Botanical Gardens, P.O. Box 1887 Gimlemoen, N-4686 Kristiansand, Norway. \\ E-mail: roar.solheim@kristiansand.kommune.no
}

\begin{abstract}
Moult of primary and secondary flight feathers of Snowy Owls Bubo scandiacus was studied from 53 museum specimens retaining some juvenile feathers. There were no ringed Snowy Owls of known age in the skin material, and the moult pattern has thus been interpreted using the moult of Eagle Owls Bubo bubo as a model. The difference between juvenile and adult primaries is described. Greater coverts may facilitate age determination of single flight feathers. Snowy Owls start their first flight feather moult M1 by shedding the innermost 2-6 secondaries during their second summer (as 2C birds). A majority of the owls also shed primary P7 during this first moult, occasionally also P8. This moult progresses at a faster pace than seen in Scandinavian Eagle Owls. During their second flight feather moult M2, moult of secondaries advances outwards, including moult from the two focal points S2 and S5, as in the Eagle Owl. Both P7 and P8 are moulted and fresh after M2, and some owls even moult P6 or P9. After the third flight feather moult M3 it is very hard to distinguish juvenile secondaries from old M1 secondaries, and a specific moult pattern is most easily recognized in primaries. On sharp images of the upper side of wings on a flying Snowy Owl, or on birds in hand, it should be possible to age birds up to four calendar years (4C) in autumn and five calendar years (5C) in spring, before onset of the fourth flight feather moult M4.
\end{abstract}

Key words: owls; snowy owl; moult; ageing

\section{INTRODUCTION}

With the exception of Tamaulipas Pygmy Owl Glaucidium sanchezi, the Snowy Owl Bubo scandiacus is the only owl species with distinctive sexual dimorphism in plumage (del Hoyo et al. 1999), with males being more white and unspotted than females. There are several descriptions of the plumages of Snowy Owls, and how to sex and age them (Portenko 1972, Josephson 1980, Cramp 1985, Olsen \& Fredriksson 1992). However, there are substantial individual variations in plumage within the same sex and age groups, with a great potential for making misjudgements. In 2003-2004 I photographed all (approximately 400) Snowy Owl skins in the main Natural History Museums in Norway, Sweden, Finland and Denmark to review the sex and age categorization of this material (Solheim et al. 2004). I soon realized that the individual variation of these birds is quite complex, and that ageing and even sexing of Snowy Owls is not as straight forward as described. The reviewing of the skin material has thus undergone several revisions, especially after discussions with other people with extensive field experience from working with Snowy Owls.

\section{MATERIAL AND METHODS}

The study is based on skins from the Natural History Museum of Stockholm (NRM), the Zoological Museum of Oslo (ZMO), the Zoological Museum of Copenhagen (KZM) and the Smithsonian Institution, Washington (SMS). A specimen from the Zoological Museum, Helsinki (HZM) is also incliluded. I examined a total of 378 Snowy Owl skins, of which 53 birds had recognizable juvenile feathers making a categorisation possible. There were 20 males and 33 females. The material covered the whole Arctic, with skins from Greenland (20), Norway, Sweden and Denmark (14), Iceland (1), North America (9) and Russia (5). Four skins lacked data on locality. No major differences seem to exist in the flight feather moulting pattern between males and females. A study of moult in Eagle Owl was done on skin material from the Natural History Museum of Stockholm (NRM), which holds a substantial number of Eagle Owl skins from ringed birds with confirmed age (Solheim 2011b). There were no ringed Snowy Owls in any of the museum collections I visited. I used the sequence of wing feather moult during the first moults of Eagle Owls as a reference for grouping the Snowy Owls into moult groups of similar 
patterns.

Most recent skins at NRM have been prepared with one free, outspread wing, perfect for wing feather moult studies. However, as most Snowy Owl skins are quite old $(100+$ years $)$, the vast majority of these skins are made with both wings folded along the body of the bird. To study differences in moult patterns of such wings you have to carefully spread out some of the flight feathers one by one to compare differences in dark spots and hue, wear and bleaching. This can be done with the primaries without harming the skin, and it is also possible to photograph these feathers. The secondaries are however harder to study, because you must carefully bend out one or a few feathers at a time, taking care not to damage the skin. It is not possible to get good photos of the secondaries of such skins. A few recent Snowy Owl skins have however been made with one outstretched wing, and these provide some good examples of the first moult of secondaries.

I have used the ageing categories for birds proposed by Runde (1991). A bird is said to be in its first calendar year (1C) from the time of hatching until 31 December. In the following year it is $2 \mathrm{C}$, and so on. A bird of unknown age, but at least in its $\mathrm{X}$ calendar year, is termed XC+. I have added the suffixes "a" (autumn) for birds found in July-December, and "s" (spring) for birds found in January-June. During summer of their second year of life (2C), Snowy Owls moult their first flight feathers, and this moult is termed M1. Next year they enter M2, and so forth.

In the Great Grey Owl Strix nebulosa and Eagle Owl, there is a distinct difference between juvenile and later wing feathers (Solheim 2011a, b). As long as some juvenile feathers can be found in the wing, it is possible to age the bird. When all wing feathers have been moulted once, it is not possible to judge the correct age of the bird after $4 \mathrm{C} / 5 \mathrm{C}$ for Great Grey Owls, and $5 \mathrm{C} / 6 \mathrm{C}$ for Eagle Owls. In Snowy Owls I was able to distinguish between juvenile and adult primaries, especially when both types are present in a wing. Also primary and secondary coverts usually show distinctive juvenile and adult patterns. For the secondaries I was not able to recognize a distinctively juvenile pattern. However, as feathers age, it is usually possible to see if there are two, and sometimes three, age classes of secondaries in the wing. The pattern of dark spots or bands may also act as a clue to distinguishing feathers of the same age class. Coverts are usually moulted together with the underlying primary or secondary. As greater coverts seem to show a more distinctive difference between juvenile and adult feathers, they can act as a clue to judging the status of the secondaries. Also the ageing of problematic primaries can be eased by the status of the primary coverts.

Four birds from July were not included when making the moult schemes, because these birds may not yet have completed their wing feather moult, and as such may show a pattern that could be misinterpreted.

\section{Recognizing juvenile feathers}

Juvenile primaries often show mottling between the dark bands towards the tip of a feather. Such mottling is common in both males (Appendix 1.1) and females (Appendix 1.2). There is however considerable variation, and some birds may show very little or no mottling at all, resembling much older birds. Mottling in the coverts may help to reveal the true feather status in such individuals (Appendix 1.3). The primaries and secondaries of juveniles also show an even pattern of spots and bands, with no abrupt changes from one feather to its neighbours. Juvenile primaries are more pointed than primaries of later generations, but these differences are most easily detected when both generations are still present in the wing. However, with experience, it should be possible to recognise a single, juvenile primary feather. In both males and females the terminal dark band of the primaries P7-10 extends almost to the tip, with a very narrow white fringe which may be missing in a few individuals (Appendix 1.1 and 1.2). In females the dark bands stretch across both outer and inner vane, while in males the band usually stops halfway across the inner vane. In older feathers the inner vane bands are usually shortened (females) or completely lost (males).

The secondaries of juveniles are evenly spotted and show no abrupt differences between feathers (Appendix 1.3 and 1.4). In spring from March the tertials and innermost secondaries become gradually more worn and bleached, until they are almost worn down to white in June (Appendix 1.3 and 1.4). This bleaching and wear seems to be more heavily expressed in juveniles than in many older birds.

In the moult pattern scheme non-moulted secondaries have been termed as juveniles in the $2 \mathrm{Ca} / 3 \mathrm{Cs}$ birds. In later stages, feathers are termed $\mathrm{O}$ (old) in contrast to $\mathrm{N}$ (New). In moult category M2 (3Ca/4Cs), any "old" secondary S11-S16 has been judged to be a formerly moulted, non-juvenile feather, while the rest of the "old" secondaries are judged to be juvenile. This interpretation is based on the moult pattern of secondaries in Eagle Owls after M2 (Solheim 2011b).

\section{Recognizing non-juvenile feathers}

The first non-juvenile primaries and coverts are usually recognized by the lack of mottling between dark bands. This is best seen when new feathers contrast neighbour, juvenile ones, both in coverts (Appendix 1.5) and in primaries (Appendix 1.6). The tip of a non-juvenile primary appears more rounded as opposed to juvenile 

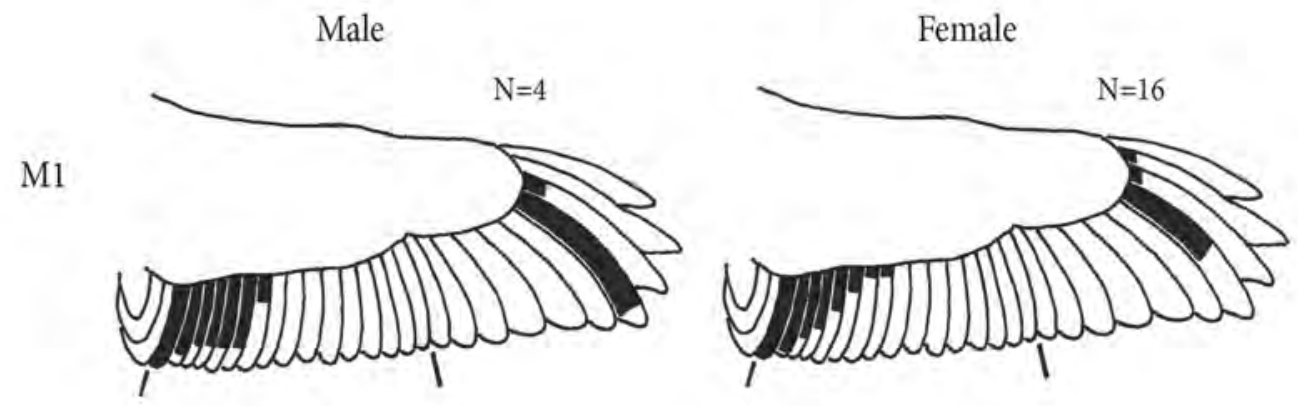

a
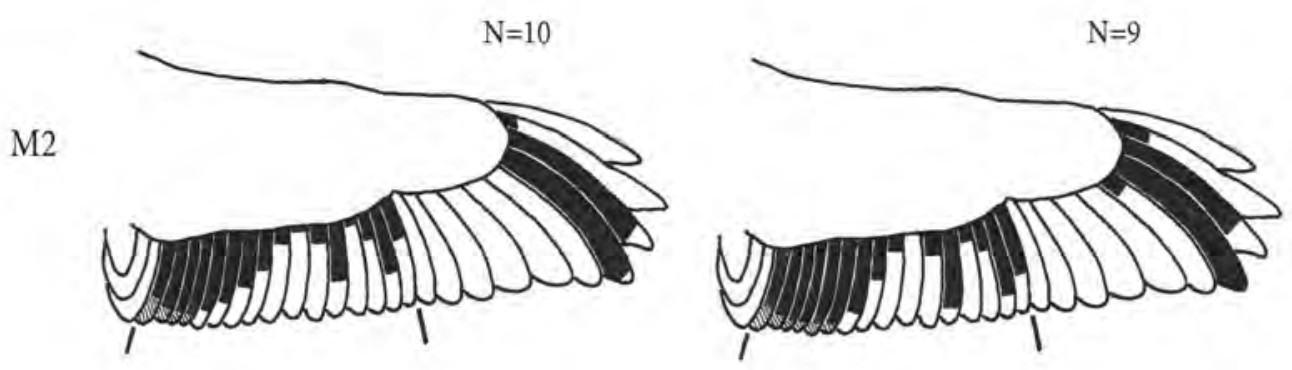

b
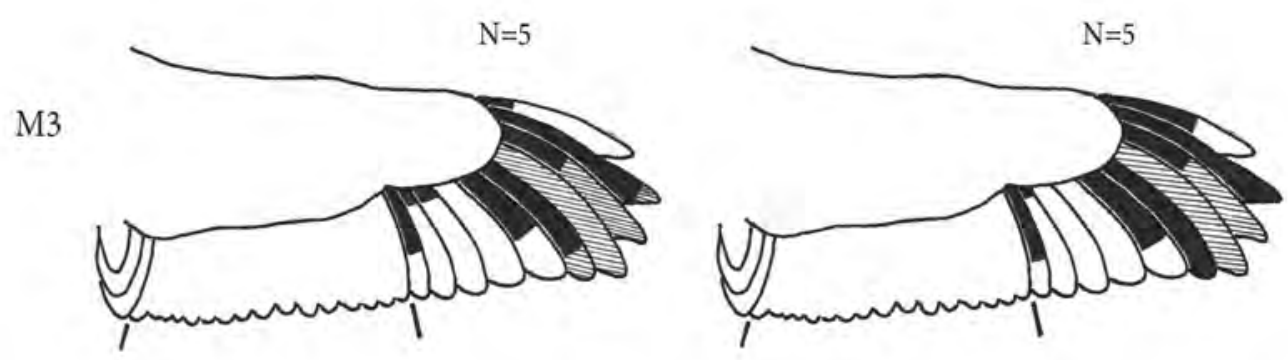

$\mathrm{C}$

Figure 1. Schematised pattern of first (M1) and second (M2) flight feather moult, and third (M3) moult of primaries of male and female Snowy Owls, based on studies of skinned museum specimens. The amount of black on each feather indicates the proportion of individuals having moulted this feather at this stage. The amount of white indicates the proportion of individuals with juvenile feathers. Hatched indicates proportion of non-juvenile feathers moulted during the previous moult phase. Tertials, and secondaries of M3 are not included in the analysis (see also Appendix 1 for details).

primaries, a feature that is underlined by a broader terminal white fringe (Appendix 1.5 and 1.6). Usually the white fringe of a non-juvenile feather is markedly broader than in juvenile feathers, which may lack a white fringe altogether (Appendix 1.7). However, sometimes non-juvenile primaries may only be distinguished from juvenile ones by their lack of wear and bleaching as opposed to neighbouring feathers (Appendix 1.8). In females the distance between dark bands on the primaries may increase as opposed to the first, juvenile primaries, and the band usually extends only halfway across the inner vane of the feather (Appendix 1.9). Also in males the number and length of terminal dark bands may decrease from juvenile to next generation primaries, but the distinction may be harder to recognize than in females (Appendix 1.10).
New primaries also in males usually get a broader, white fringe than on juvenile feathers (Appendix 1.11).

\section{RESULTS}

\section{First moult M1}

The Snowy Owls start their flight feather moult with the tertials and innermost 2-6 secondaries (Figure 1a, Appendix 2). The four males judged to be in this category had all lost primary P7 on both (3) or at least one (1) wing. The last bird was however from 16 August, and may not yet have completed moulting. One male had also moulted $\mathrm{P} 8$, on his right wing only. There were 19 females with the same pattern of secondaries 
moult, and thus judged to be in the first moult category. Of these, 10 had not moulted any primaries, while 9 had moulted primary P7. One female had also moulted P8 and P9, however on one wing only. At this stage it is very easy to see the difference between P7 and P6, because the tip of P6 is very exposed on a resting bird, and heavily bleached and abraded. This feather will also stick out as more worn than P7 in 2Cs birds before their first wing feather moult. Moult pattern in both wings was checked on 20 of the 23 M1 birds. Of these only 6 showed asymmetrical moult patterns.

\section{Second moult M2}

In their second wing feather moult (as 3C birds), all birds had moulted P7, and most had moulted P8 (Figure 1b, Appendix 2). One male and two females had also moulted P9. The birds had now started moulting secondaries from the same two focal points (S2 and S5) as seen in Eagle Owls. From the innermost part of the wing, moult advanced outwards. In males S13-S16 were now completely moulted, while in females S11S16 were all moulted. Nine of 19 birds had moulted S1, and only one bird had moulted S7. All birds had now moulted P7 (one bird had moulted P7 on one wing only), and most birds had also moulted P8. Some had even moulted P6 or P9. One female had moulted both P6 and P9. Moult pattern could be checked for both wings on 18 of the 19 M2 birds, and 11 of them showed asymmetrical patterns.

\section{Third moult M3}

At this stage I have only drawn moult patterns of the primaries (Figure 1c), because it is almost impossible to judge if an old, abraded secondary is a non-moulted juvenile feather, or a moulted feather from M1 or even M2 (but see Appendix 2). After M3 all birds had moulted P6-P9, with P7 (and P8 in some birds) standing out as clearly lighter and more worn than the neighbouring, fresh primaries of $\mathrm{N} 2$ generation (Appendix 1.12). More than half of the birds had started moulting from P1, and had also lost P5. The feature separating this moult category from the previous M2 is the marked contrast in hue and abrasion between P7-8 and the newly moulted primaries both inwards and outwards, and the start of moulting from P1 outwards. In all birds P4 was still juvenile, and for most birds also P2 and P3. Moult was checked on both wings for 10 of the $11 \mathrm{M} 3$ birds, and all showed asymmetrical moult patterns.

\section{DISCUSSION}

Based on the moult schemes presented here, it should be possible to determine the age of Snowy Owls up to $4 \mathrm{Ca} / 5 \mathrm{Cs}$ with certainty. It may even be possible to follow the moult pattern into stage M4, provided that some juvenile feathers are still present in the wing. Extensive collecting of wing photos of live birds could probably help to determine if ageing is possible at this stage. To correctly age a bird with a fresh non-juvenile P7 one should get good views of the outer half of the secondaries. A bird with homogenously patterned secondaries $\mathrm{S} 1-\mathrm{S} 8$ should be aged $2 \mathrm{Ca} / 3 \mathrm{Cs}$, while a bird with fresh, non-juvenile secondaries S2 and S5 should be aged $3 \mathrm{Ca} / 4 \mathrm{Cs}$.

The material in this study included birds from all major parts of the species' Holarctic distribution. The Snowy Owl is a monotypic species with no distinctive subspecies or subpopulations, a conclusion also supported by DNA studies (Marthinsen et al. 2008). One should thus not expect to find marked differences in moult patterns in birds from different parts of the Holarctic, as pointed out also by Pyle (1997).

The sequence of flight feather moult found in this study follows the same pattern as that described by Pyle (1997), however Pyle did not recognize the distinctive two focal points of secondaries S2 and S5 for Snowy Owls or other Bubo species. These focal points are very distinctive during second moult M2 for both Snowy and Eagle Owls (Solheim 2011b). The proportion of birds with asymmetrical moult pattern when comparing right and left wing steadily increased from M1 to M3, with all M3 birds being asymmetrical. Also Pyle (1997) found that most of the Snowy Owls and Great Horned Owls Bubo virginianus studied in North America showed asymmetrical moult patterns after M3.

In the Swedish Eagle Owl material, the birds only moulted the innermost secondaries S13-S15 during their first flight feather moult (Solheim 2011b). Spanish Eagle Owls however also moulted one or two primaries (P7 and P6) during their first wing feather moult (Blasco-Zumeta 2010). Difference in prey abundance between Scandinavia and Spain may explain why Spanish Eagle Owls moult at a quicker pace than the more northern birds. Snowy Owls with no moulted secondaries in focal points S2 and/or S5 are thus more likely to be in moult stage M1 than M2, although they may have started moulting primaries P7 (and in some events even more primaries). Snowy Owls thus seem to have a more extended M1 moult than northern Eagle Owls. Also the moult pattern after M2 supports this interpretation of the Snowy Owl moult. Both during breeding and in their winter habitats, Snowy Owls inhabit more extreme ecosystems than northern Eagle Owls. It is thus puzzling that their first wing feather moult seems to include more feathers than in Scandinavian Eagle Owls.

In Ural Owls Strix uralensis the number of moulted flight feathers has been shown to be negatively correlated with the number of offspring produced by the 
adult during the same summer (Pietiäinen et al. 1984). Since neither Snowy Owls nor Eagle Owls are likely to start breeding during their second year, it is unlikely that the variation in number of moulted flight feathers in stage M1 (and even M2) is linked to reproductive investment. Although Snowy Owls inhabit more extreme breeding habitats with fewer potential prey species than Eagle Owls, they are not bound to a fixed territory like Eagle Owls. The nomadic behaviour of Snowy Owls may thus allow them better nutritional resources than the larger stationary Eagle Owl.

Ackowledgements. I thank the Natural History Museums in Helsinki, Stockholm, Oslo and Copenhagen, and the Smithsonian National Museum of Natural History (Washington) for granting me access to their skin collections. The Norwegian Directorate for Nature Management supported this study by covering some of the travel expenses, of which I am very grateful. I also thank Irina Menyushina, Vidar Selås and Ingvar Byrkjedal for valuable comments on the manuscript, and David H. Johnson for helpful support during my visit in Washington and information on American literature.

\section{REFERENCES}

Blasco-Zumeta, J. 2010. Identification atlas of birds of Aragon. http://www.ibercajalav.net (accessed Sept. 2010).

Cramp, S. (ed.). 1985. Handbook of the birds of Europe, the Middle East and North Africa, Vol. IV. Terns to woodpeckers, Oxford Univ. Press, Oxford, New York.

del Hoyo, J., Elliott, A. \& Sargatal, J. (eds.). 1999. Handbook of the Birds of the World. Vol. 5. Barn-owls to Hummingbirds. Lynx Edicions, Barcelona.

Marthinsen, G., Wennerberg, L., Solheim, R. \& Lifjeld, J. T. 2008. No phylogeographic structure in the circumpolar snowy owls (Bubo scandiacus). Conserv. Genet. 10: 923-933. DOI 10.1007/s10592-008-9581-6.

Pietiäinen, H., Saurola, P. \& Kolunen, H. 1984: The reproductive constraints on moult in the Ural Owl Strix uralensis. Ann. Zool. Fennici 21: 277-281.

Portenko, L.A. 1972. Die Schnee-eule. Die Neue BrehmBücherei. A. Ziemsen Verlag, Wittenberg Lutherstadt. (In German)

Pyle, P. 1997. Flight-feather molt patterns and age in North American owls. Monographs in Field Ornithology, Number 2. American Birding Association, Colorado Springs, Colorado. 34 pp.

Runde, O.J. 1991. Ringmerkerens håndbok. Stavanger Museum, Stavanger. (In Norwegian)

Solheim, R. 2010. Kan lappugglor individ-bestämmas utan infångande och märkning? Vår Fågelvärld 69 (2): 8-12. (In Swedish)

Solheim, R. 2011a. Moult pattern of primaries and secondaries during first and second flight feather moult in Great Grey Owls Strix nebulosa. Ornis Svecica 21: 11-19.

Solheim, R. 2011b: Moult pattern of primaries and secondaries in Eagle Owls Bubo bubo. Ornis Norvegica 34: 1-9.

Solheim, R., L. Wennerberg, G. Marthinsen \& J. Lifjeld. 2004: Hvor langt vandrer snøugla? Snøuglas populasjonsstruktur belyst ved DNA-analyse av museums-materiale. Vår Fuglefauna 27: 66-69. (In Norwegian)

Received 5 September2012. Accepted 24 October 2012 
Appendix 1. Moult patterns in Snowy Owl wings according to sex and age.

Abbreviations: J: juvenile, N: new, non-juvenile feather. Numbers indicate feathers of same generation; 1 older than 2. P: primary. HZM: Zoological Museum, Helsinki; KZM: Zoological Museum, Copenhagen; NRM: Natural History Museum Stockholm; SMS.: Smithsonian Institution, Washington, ZMO: Zoological Museum, Oslo. 

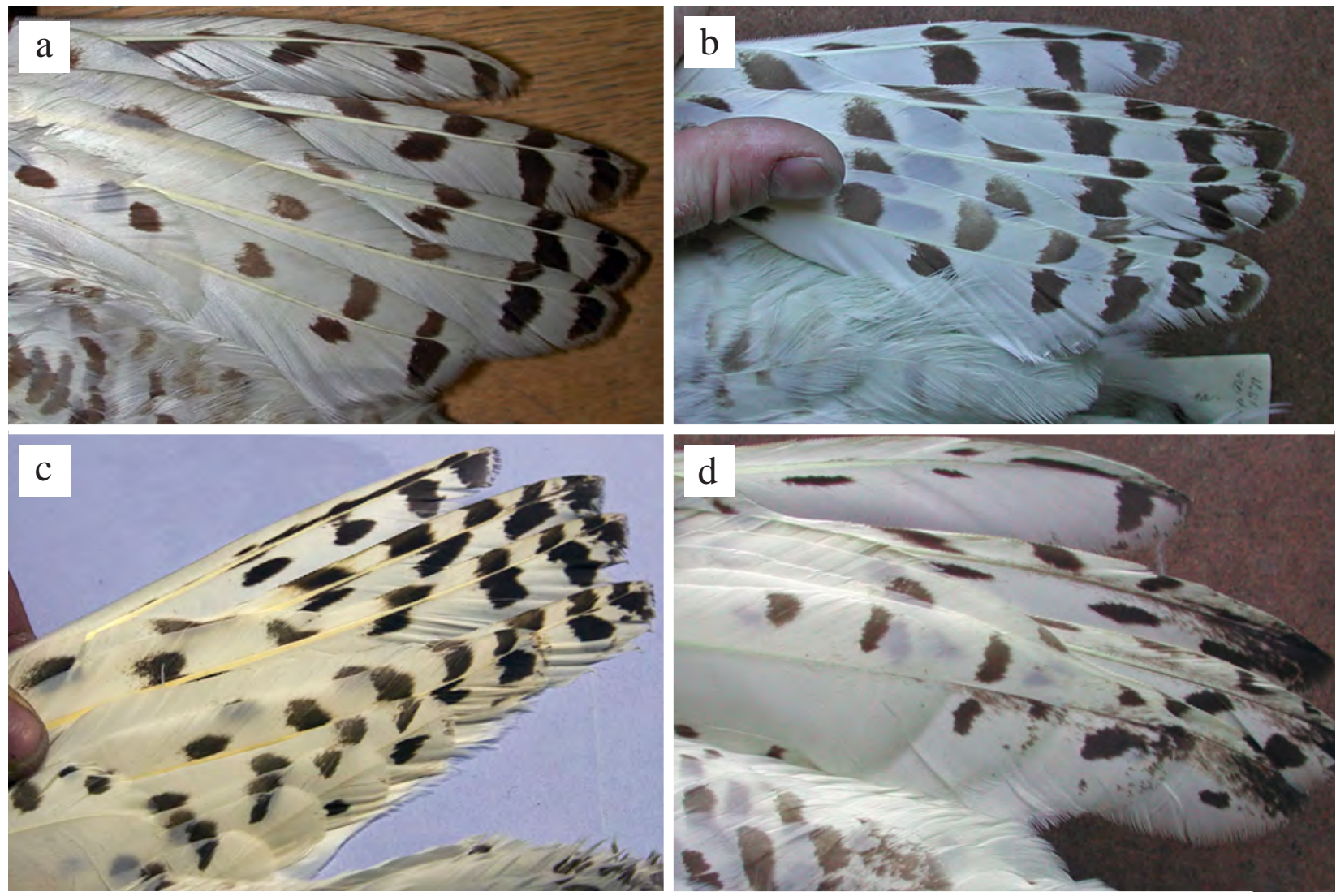

Appendix 1.1. Outer primaries of four juvenile (1Ca-2Cs) male Snowy Owls, showing variation in number and extension of dark bands and mottling. Specimen numbers: HZM8621 (a), KZM67149 (b), SMS 239186 (c) and KZM 39515 (d). 

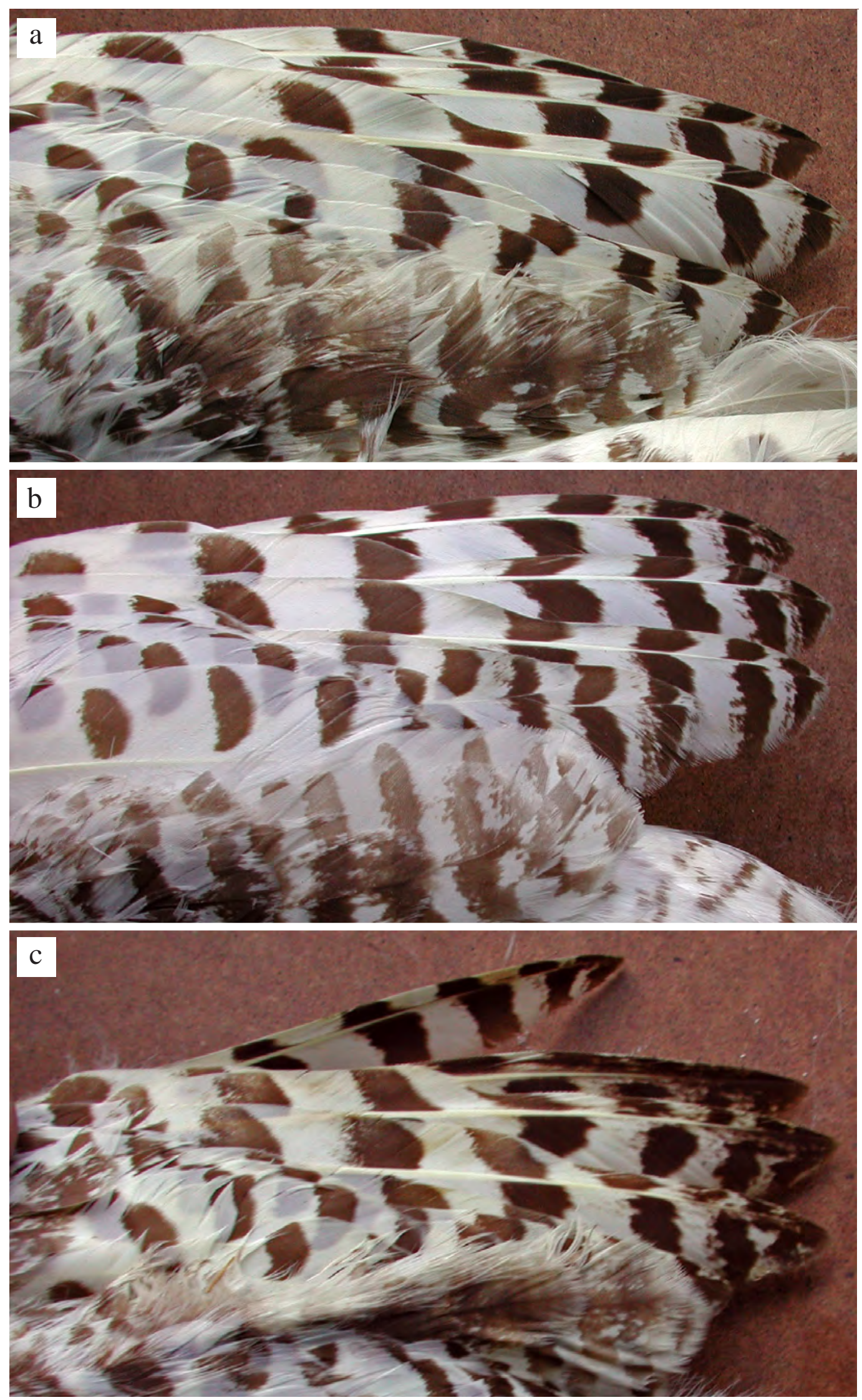

Appendix 1.2. Outer primaries of three juvenile ( $1 \mathrm{Ca}-2 \mathrm{Cs})$ female Snowy Owls, showing variation in mottling. Specimen numbers: KZM39454 (a), KZM39532 (b), KZM39473 (c). 

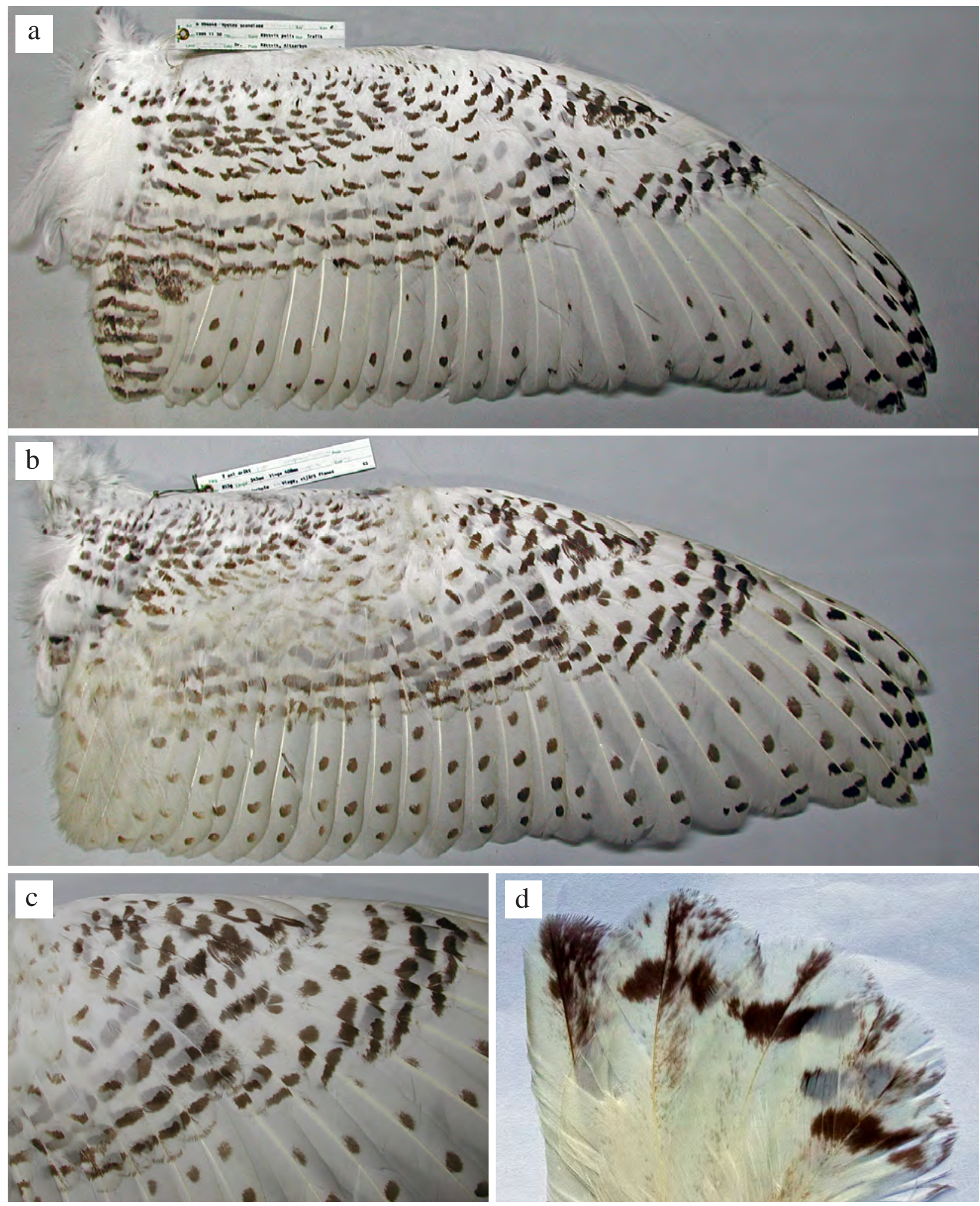

Appendix 1.3. Extended wings of two slightly mottled juvenile males from November (a) and July (b), showing difference in bleach and abrasion on tertials and inner secondaries before onset of first moult M1, and close up of primary (c) and secondary (d) coverts of two juvenile males, showing mottling on coverts. Specimen numbers: NRM996648 (a), NRM20006304 (b, c) and KZM39488 (d). 

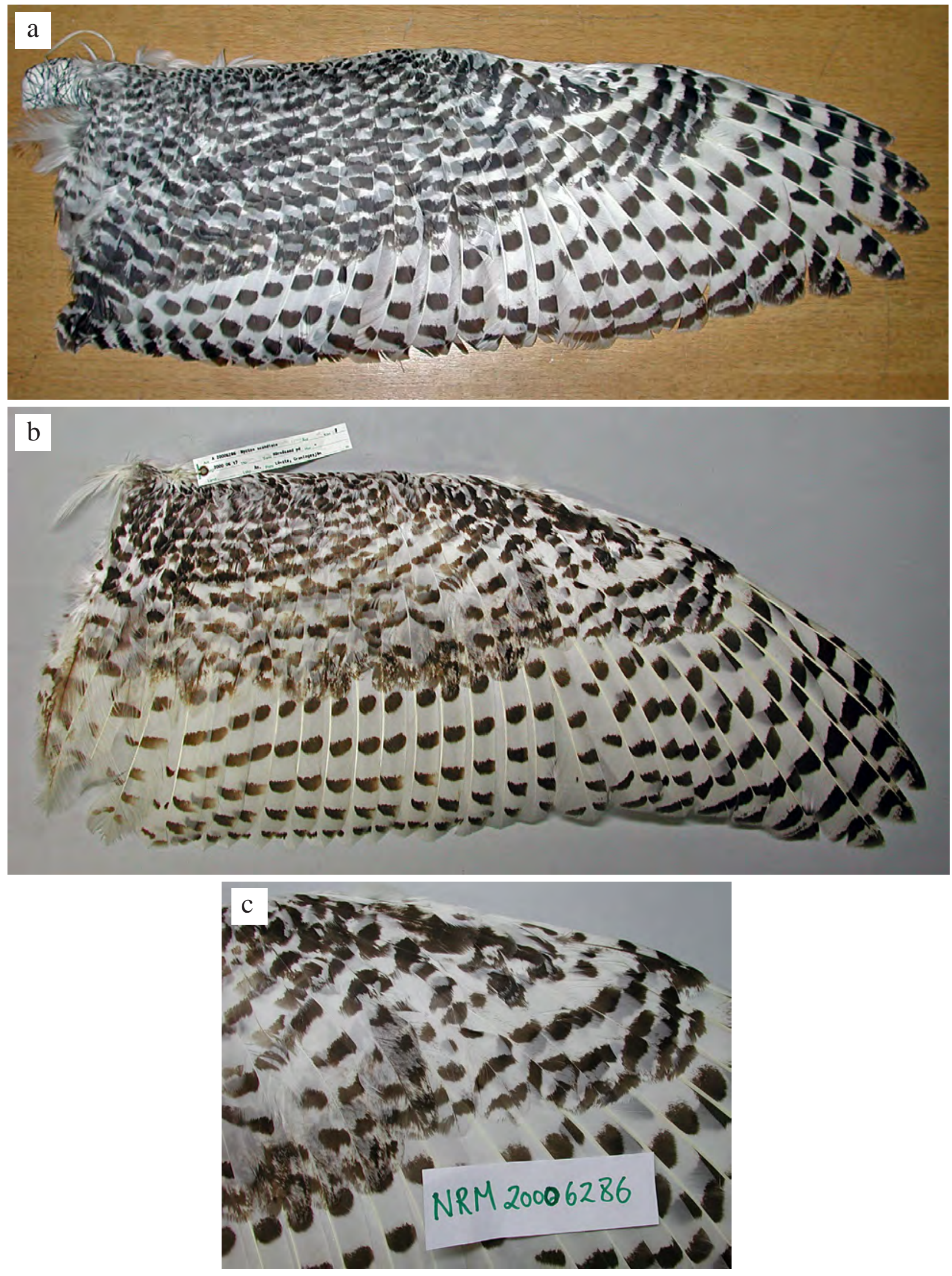

Appendix 1.4. Extended wings of two juvenile female Snowy Owls from January (a) and June (b), showing difference in bleach and abrasion on tertials and inner secondaries before onset of first moult M1, and close up of coverts of the June bird, showing marked mottling especially on secondary coverts (c). Specimen numbers: HZM24740 (a) and NRM20006286 (b, c). 


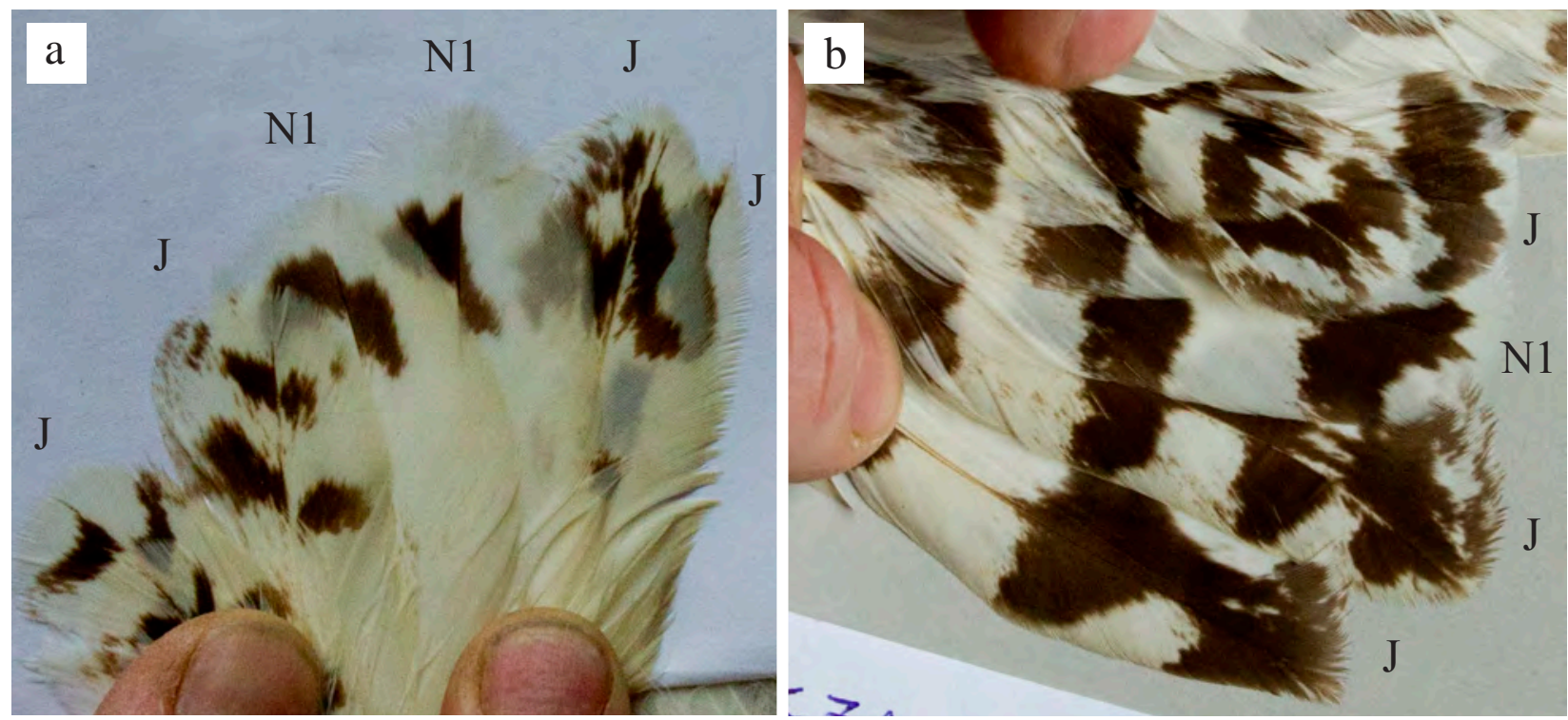

Appendix 1.5. Greater coverts of male (a) and female (b) Snowy Owls after first moult M1. J: Juvenile feather, N1: first generation of adult, non-juvenile feather. Specimen numbers: KZM39452 (a) and KZM39554 (b).

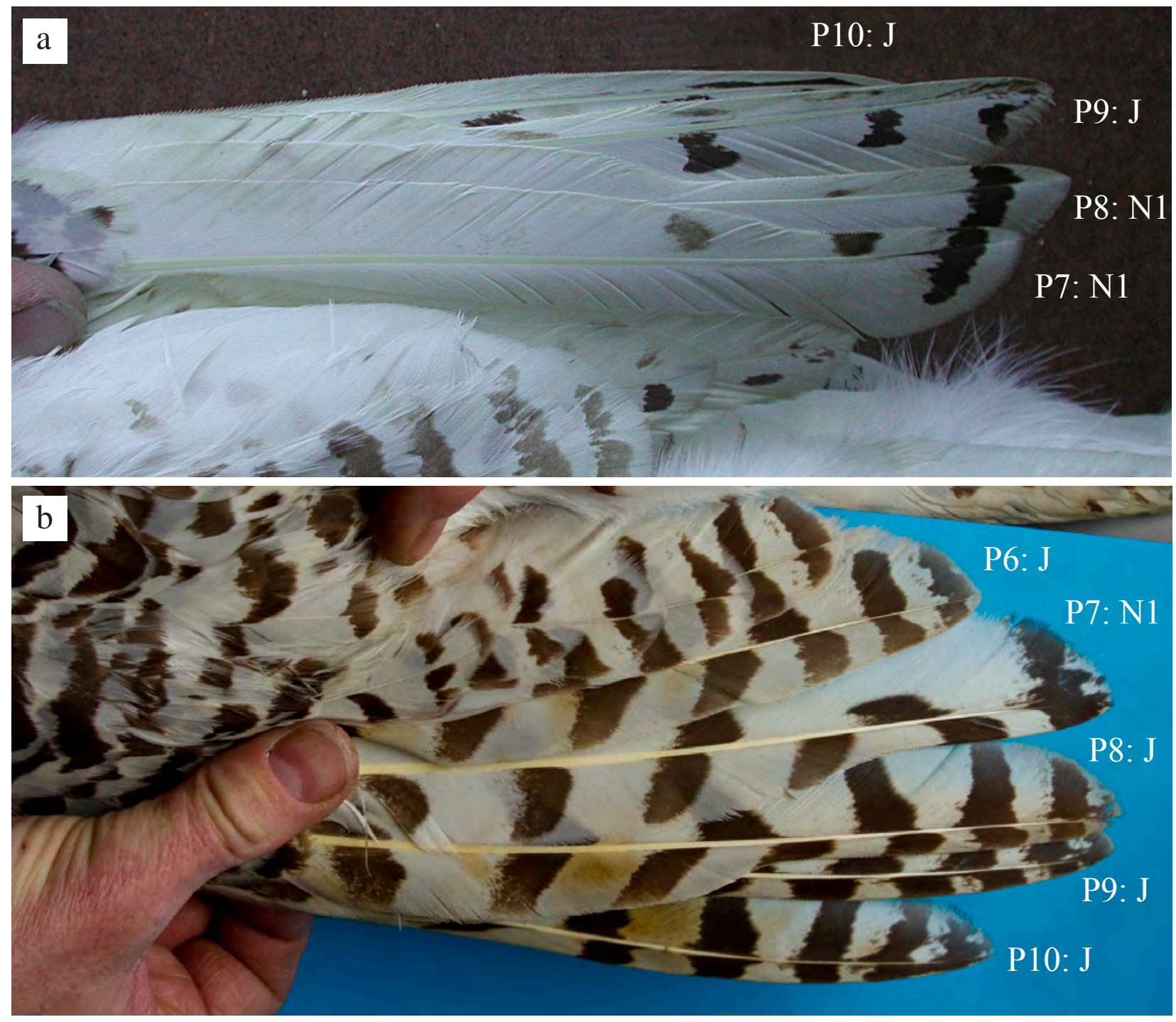

Appendix 1.6. Outer primaries of male (a) and female (b) Snowy Owls after first moult M1. J: Juvenile feather, N1: first generation of adult, non-juvenile feather. Specimen numbers: KZM39452 (a) and KZM39554 (b). 


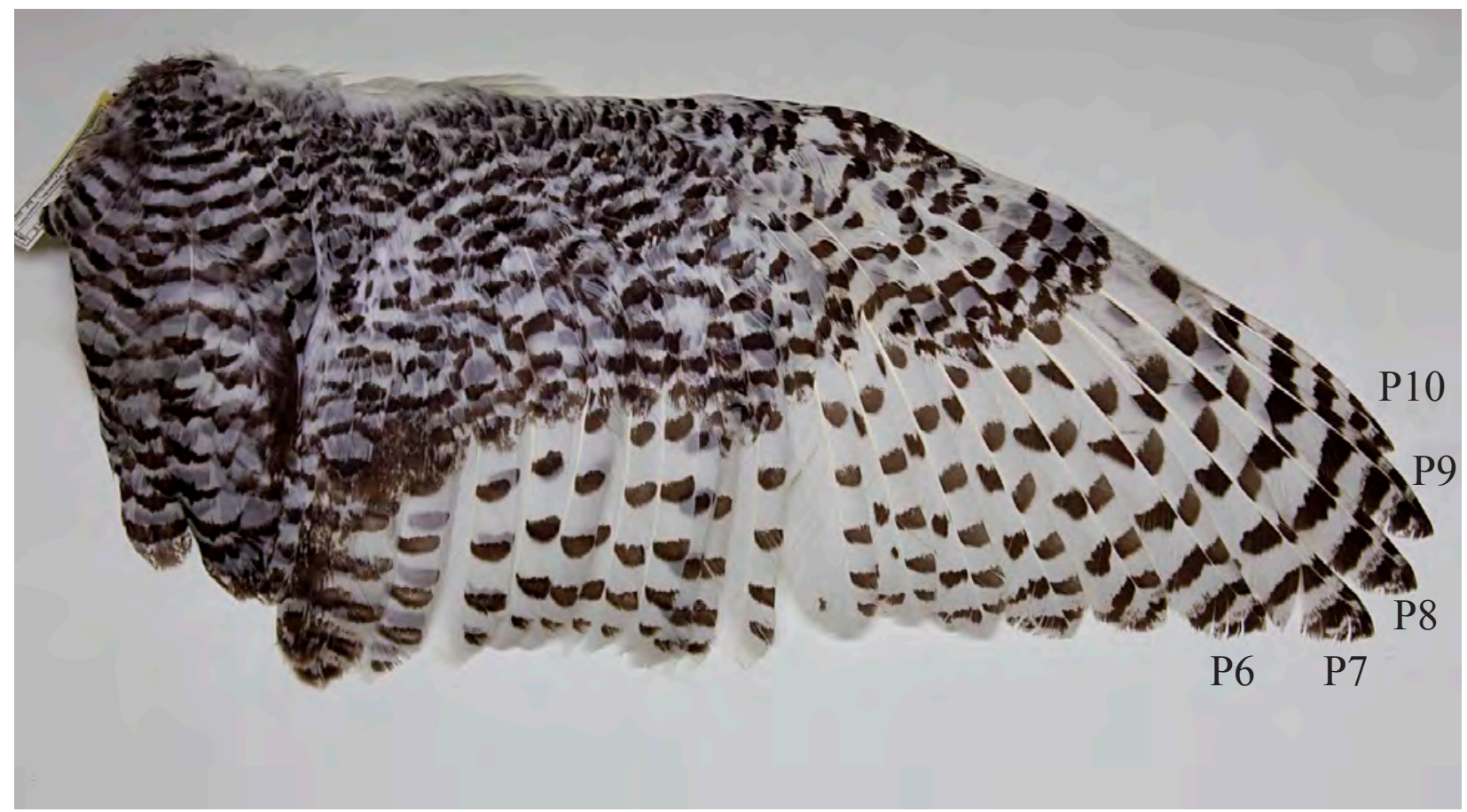

Appendix 1.7. Wing of 2Cs female from 28. January, with primaries P6-P10 showing lack of white outer fringe. Note also mottling between the outer dark bands on primaries P5-9. Specimen number: SMS 614342.

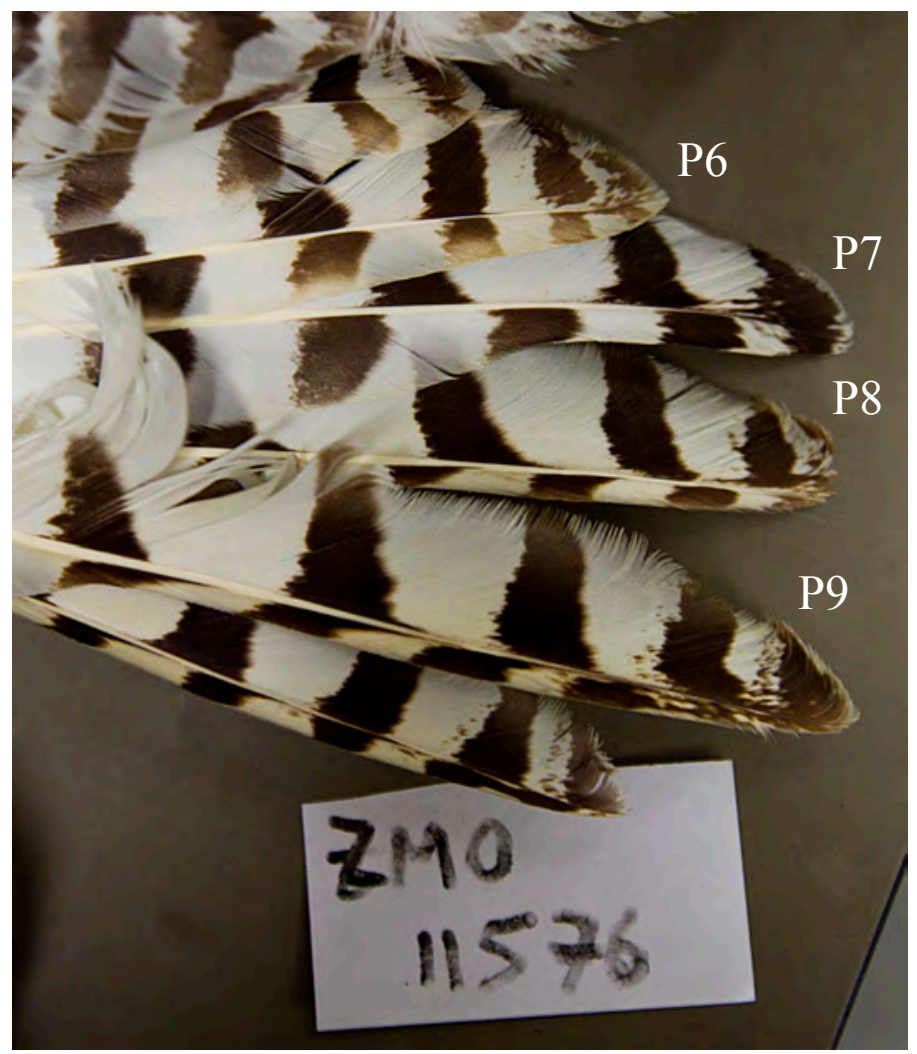

Appendix 1.8. Primaries P5-10 of a 3Cs female January. P7 is not easy to distinguish as N1 compared with the other primaries. However the terminal dark band is broader than on P6 and P8. Also P7 is fresh, while P6 and P8 are abraded and bleached. Because P7 is the most exposed primary of the wing, it should have been even more bleached than its neighbours if it belonged to the same generation. 

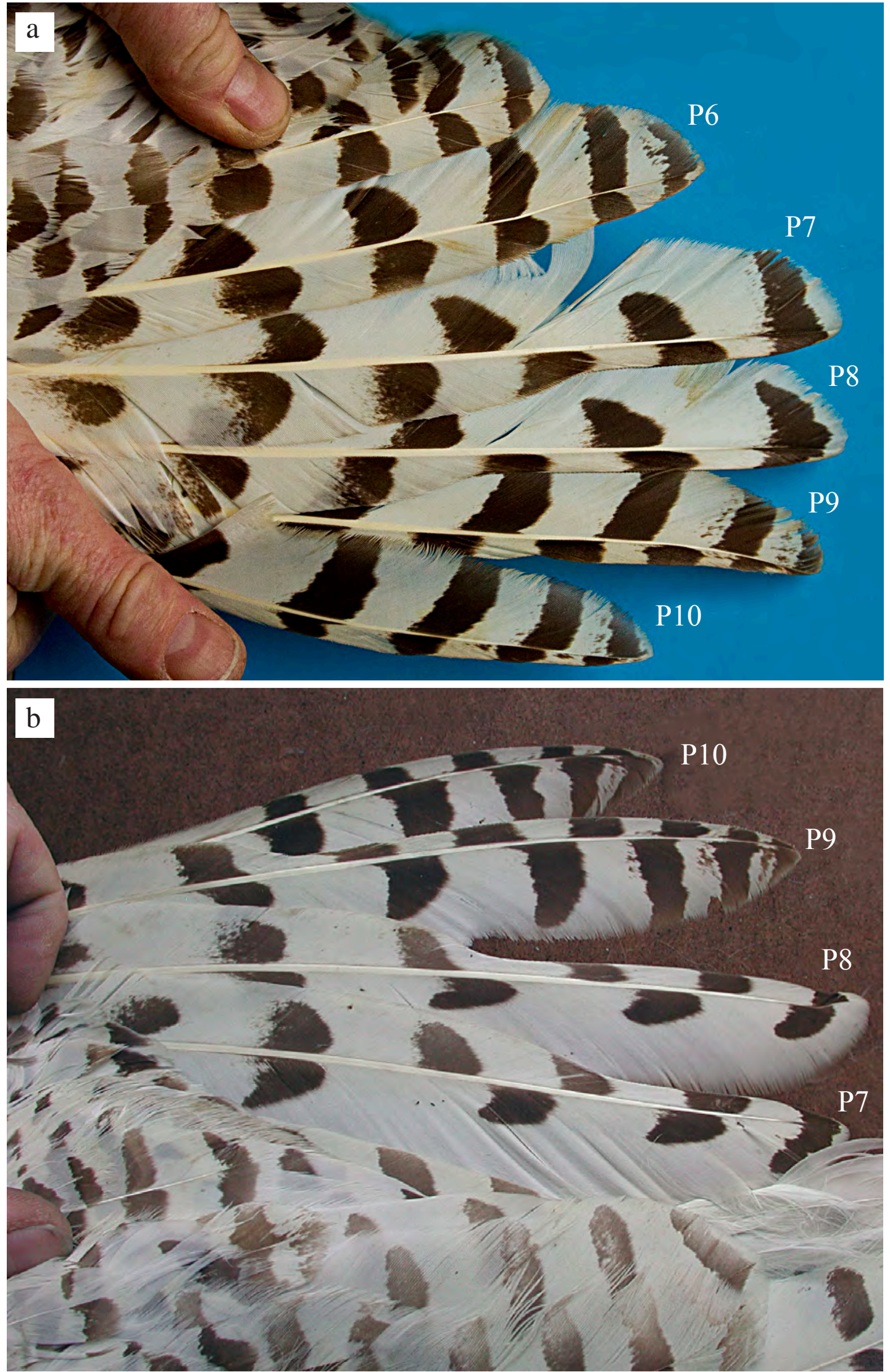

Appendix 1.9. Primaries of females after their second moult M2, 3Ca female from 5. September (a) and 4Cs female from March (b). P7 and P8 are non-juvenile, fresh feathers with marked outer, white fringe and shortened dark crossbands on inner vanes. Specimen numbers: KZM39546 (a) and KZM 39568 (b). 

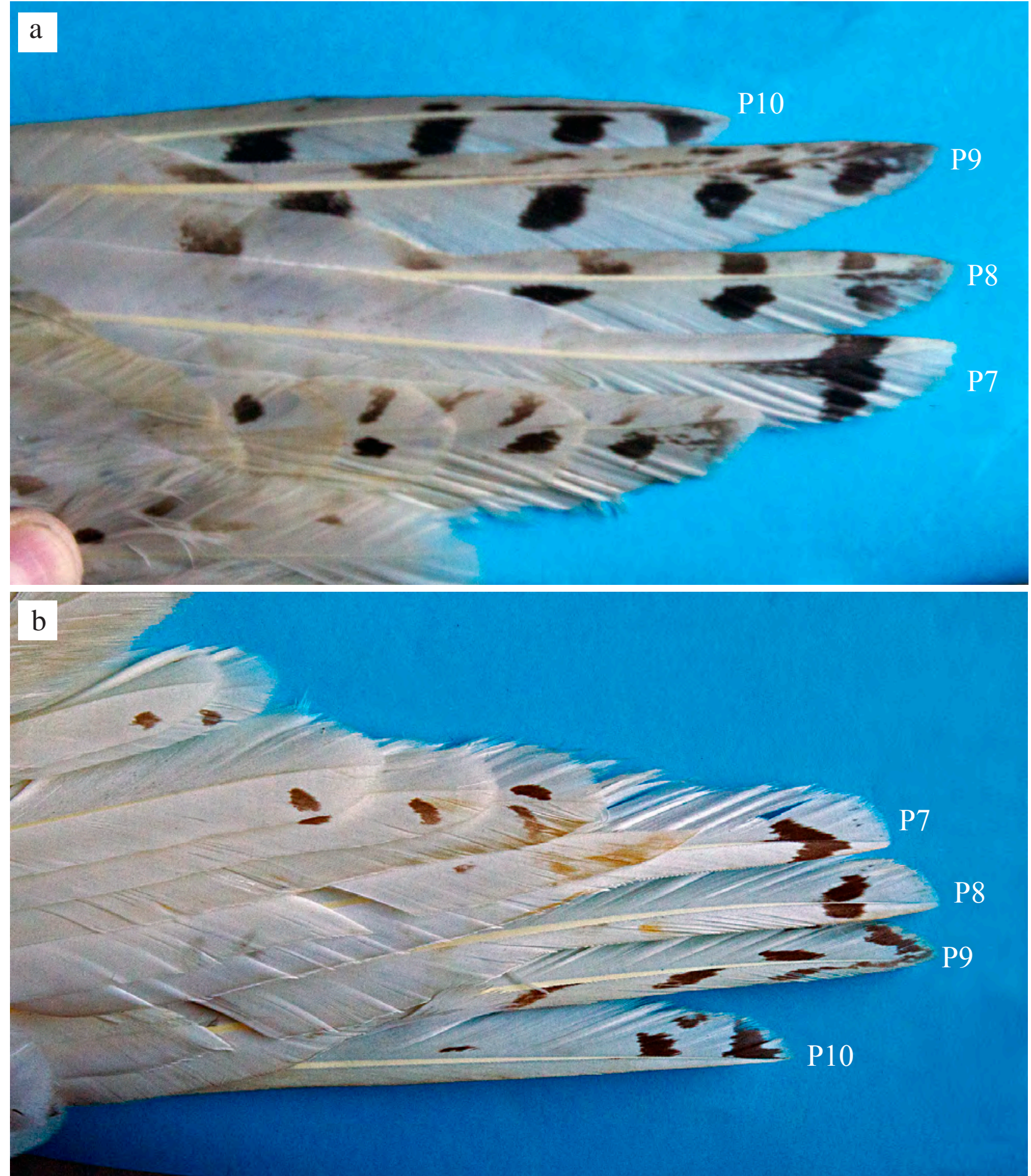

Appendix 1.10. Primaries of males after their second moult M2, both from October. In (a) only P7 is of N1 generation, in (b) both P7 and P8 are N1 generation. Note the broad terminal white fringe on the new N1 feathers as opposed to the neighbouring juvenile primaries. Specimen numbers: KZM30742 (a) and KZM39441 (b). 


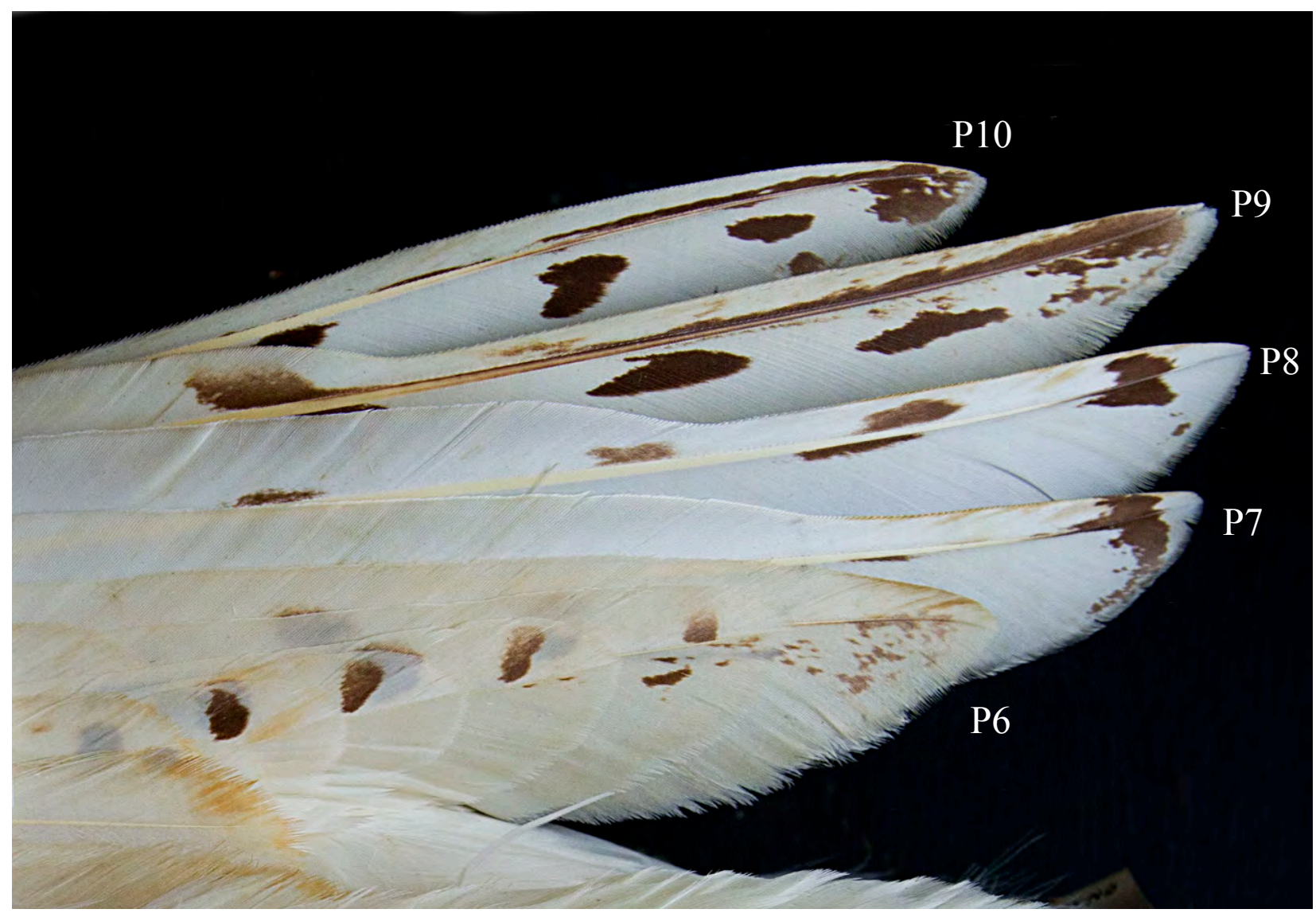

Appendix 1.11. Primaries of a 3Ca male after second moult M2, 11. November. P7 and P8 are new, N1 feathers, but may by themselves appear juvenile because of slight mottling. However compared to P6 and P9-10, they clearly stand out as non-juvenile. Specimen number: KZM39513. 

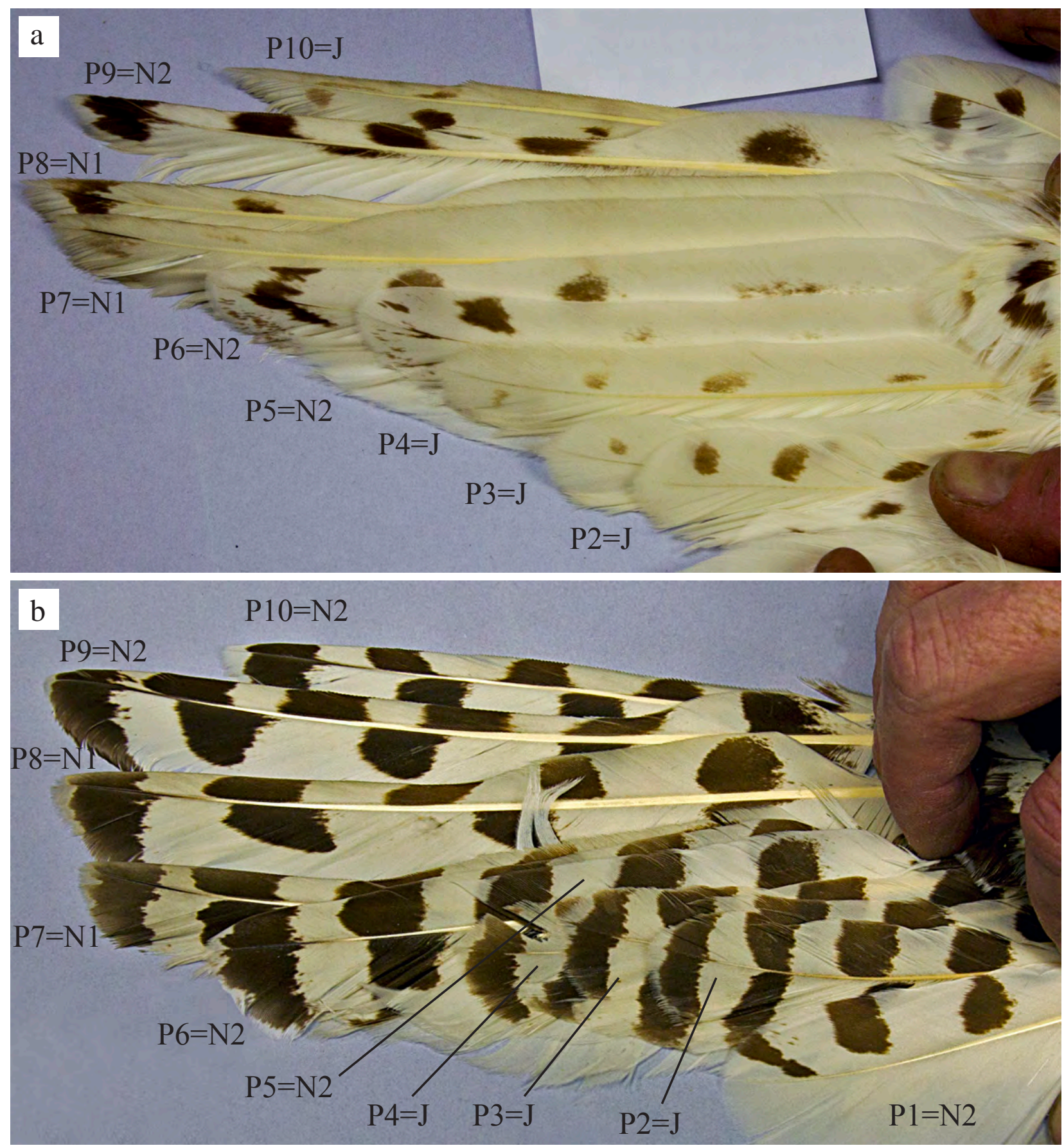

Appendix 1.12. Primaries of male (a) and female (b) after third wing feather moult M3. J: juvenile, N1: first generation adult and, N2: second generation adult feather. In the male P1 is hidden, and in the female the tip of P5 is broken. Specimen number: SMS 202672 (a) and SMS 479307 (b). 
Appendix 2. Individual data 


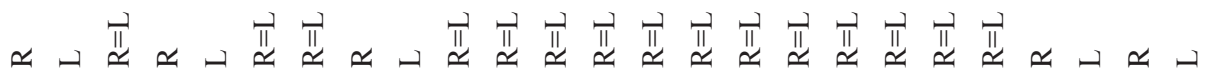
$z z z z z z,==1 z, 1 z \cdot z z z, z z z z z z$ $z \sim z z z z, a=\sim z, z z z z z z z z z z z z z$

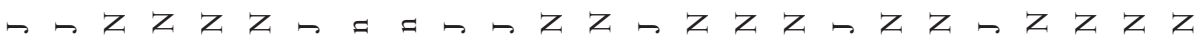
$\sim \sim z z z \sim \sim \sim \sim z z \sim z z z \sim \sim z \sim \sim z z$ $\sim \sim \mathrm{z} z \mathrm{z} z \sim \sim \sim \mathrm{z} z \mathrm{z} \sim \mathrm{z} \mathrm{z} \sim \sim \sim \sim \sim \sim \mathrm{z} z$ $\sim \sim Z \mathrm{Z} Z \mathrm{Z} \sim \sim \sim \mathrm{Z} \sim \mathrm{Z} \sim \mathrm{Z} Z \sim \sim \sim \sim \sim \sim \sim$

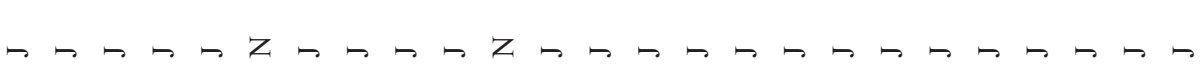

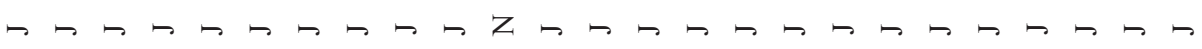

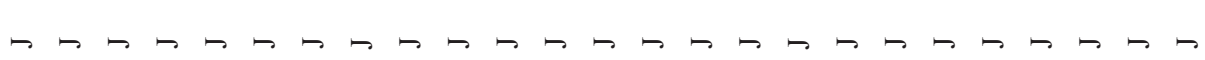

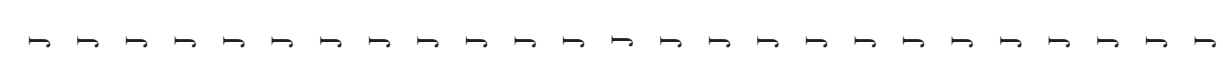

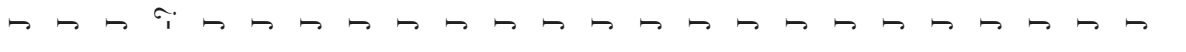

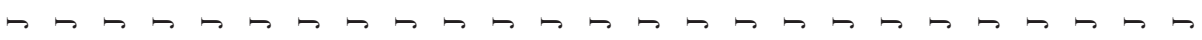

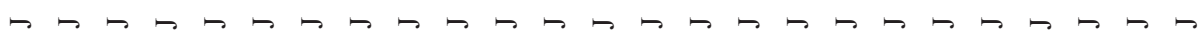

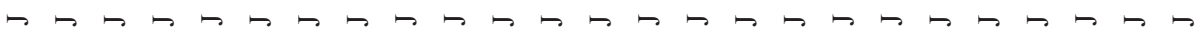

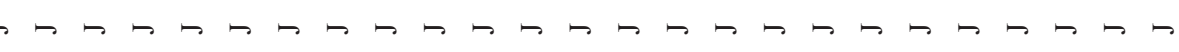

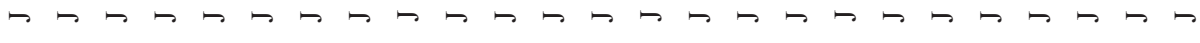

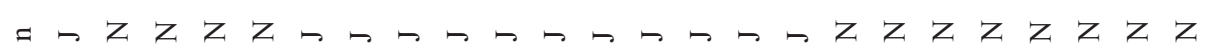

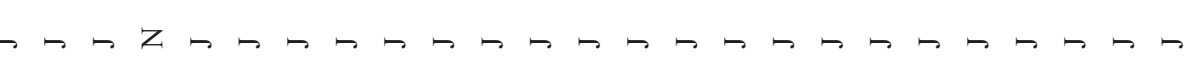

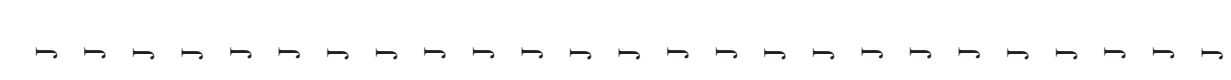

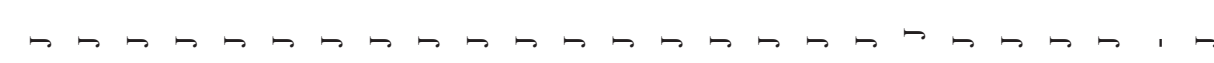

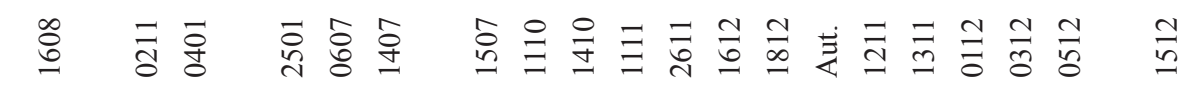
$\sum \sum \sum \sum \Psi$

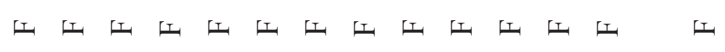
$\bar{z}$ 
$\approx \widehat{n}$

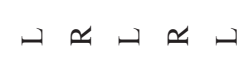
, z, , z $z z z z z$ $z z z z z$ - z z z z $\sim z z \sim \sim$ r n -2

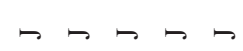

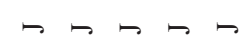

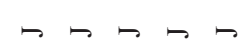

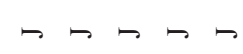

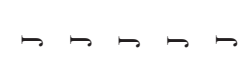

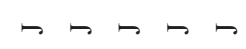

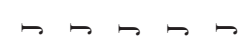

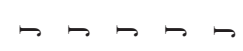

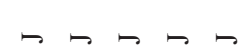
$r a r$

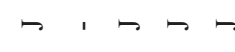
r n $n$

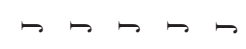

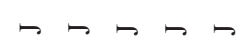

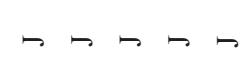

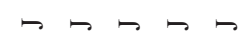
z z z z z $\mathrm{Z} \sim \boldsymbol{n}$ $\mathrm{Z} \sim \boldsymbol{\sim}$

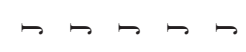
$\underset{\infty}{\stackrel{\Xi}{\leftrightarrows}} \stackrel{\overrightarrow{0}}{\sim}$

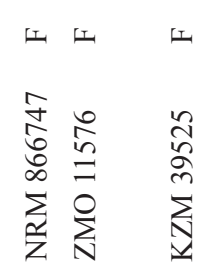

ซ -

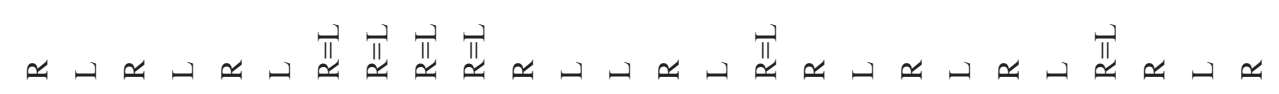
$\bar{z} \bar{z} \circ z \bar{z} z \bar{z} \circ \bar{z}, 1,0 \mathrm{z} z \bar{z} \mathbf{z} \circ 0, \dot{z} \bar{z}$ $\bar{z} \bar{z} z z z z z z \circ \bar{z}, z \circ z z z z z z z z \circ z \bar{z}$

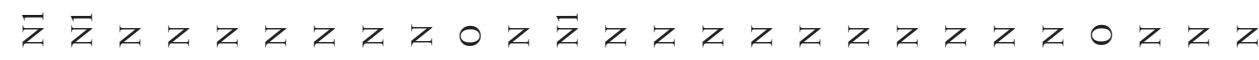
$=\tilde{z} z z z z z z \circ z \bar{z} z z z z z z z z \quad z z z$ $=00000 \mathrm{z} z \mathrm{z} \hat{\mathrm{z}} \mathrm{z} z \mathrm{z} z \mathrm{z} z \mathrm{z} z \mathrm{z} z 0 \mathrm{z} z \mathrm{z}$ $=0000 \mathrm{z} z \hat{z} 0 \mathrm{z} z \mathrm{z} z \mathrm{z} z \mathrm{z} z \mathrm{z} 0 \mathrm{z} z \mathrm{z}$ $=0000 \mathrm{z} 0 \mathrm{z} \hat{z} \circ \mathrm{z} 0 \mathrm{z} z \mathrm{z} 0 \mathrm{z} 0 \mathrm{z} z \mathrm{z} \dot{z} \mathrm{z} z$ $0=0000 z \circ 0 \hat{z} 0 z 0 z z z 0000 z z_{0} 00 i_{i}$ $000000000 \hat{z} 0000 z 0000000 z 000$ $000000000 \hat{z} 000000000000-000$ $00 z 000000 \bar{z} 00000000000 z z_{0} z_{0}$ $==z \circ 00 z z z \circ z \circ z \circ 0 z \circ z z z z z z z z 0$ $00000000000 z 0000 z 00000 n 000$ $000000 \mathrm{z} 00000 \mathrm{z}, 0 \mathrm{z} 00 \mathrm{z} 000-0 \mathrm{z}$

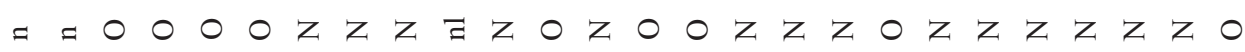

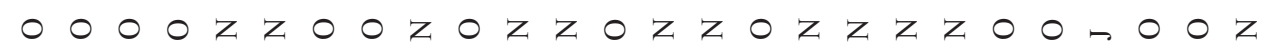

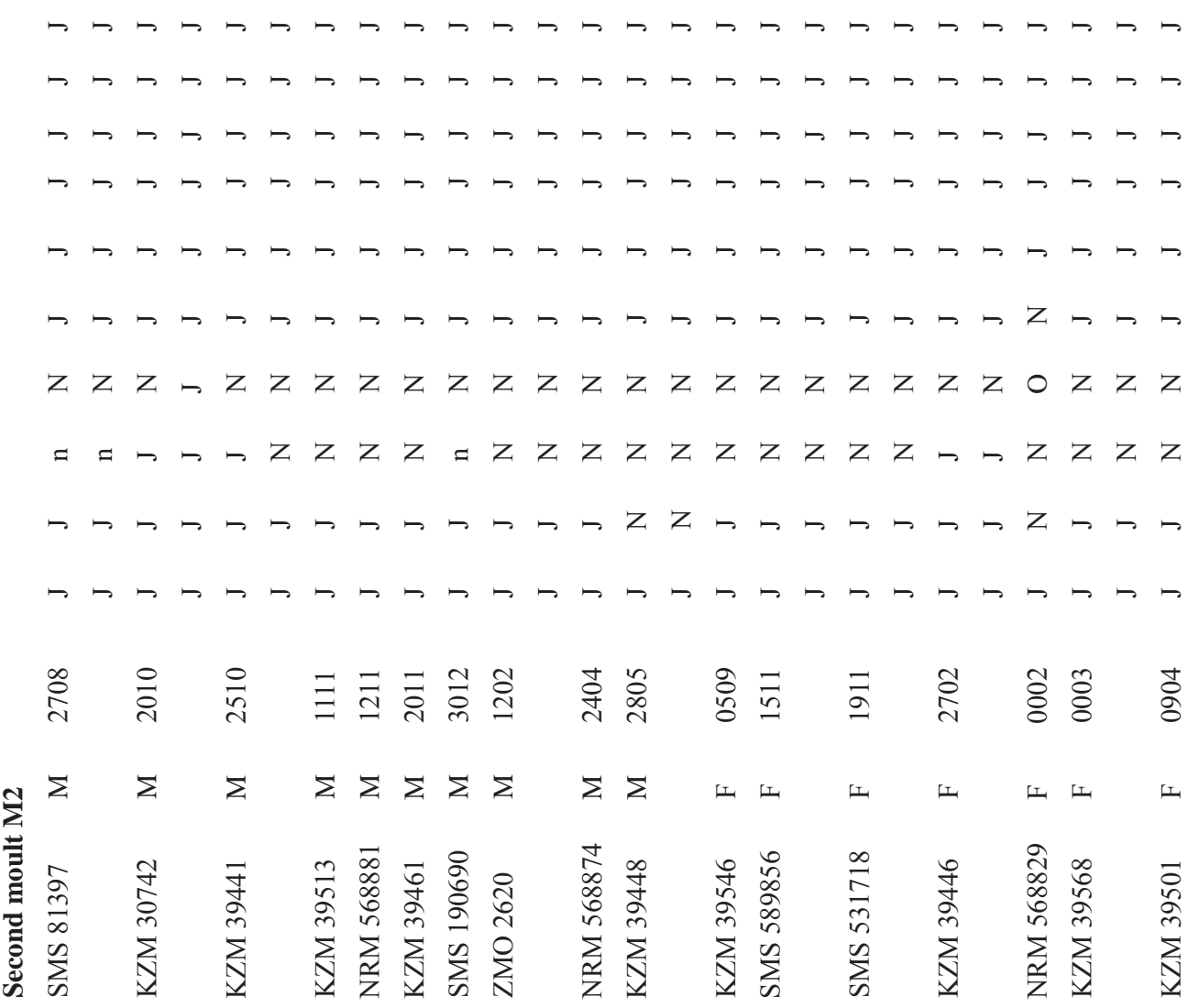


67 Solheim

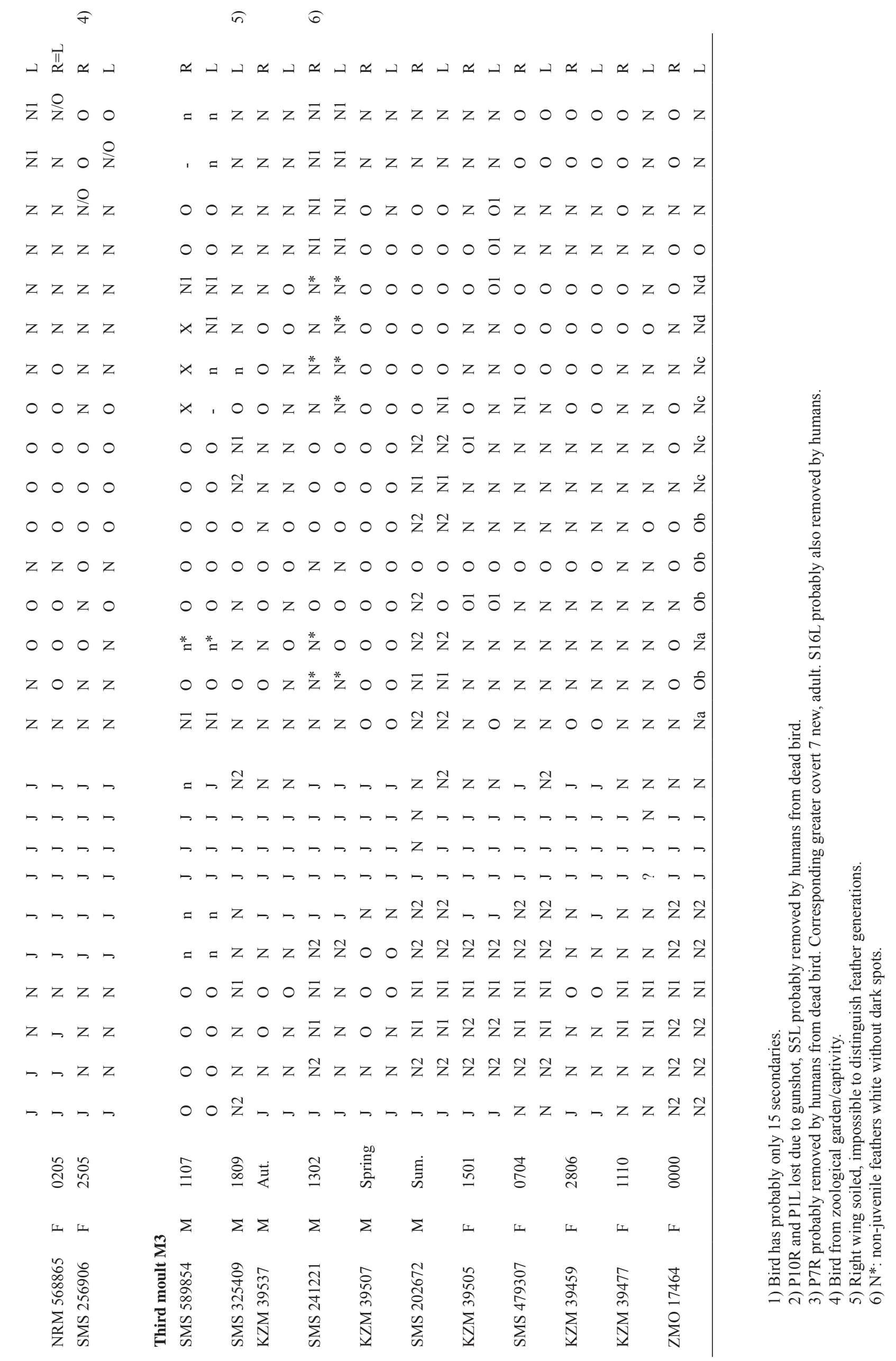

